LE MOUVEMENT DU SOLEIL PAR RAPPORT AUX GALAXIES LES PLUS PROCHES

G. de Vaucouleurs, W.L. Peters and H.G. Corwin, Jr. Department of Astronomy and McDonald Observatory

The University of Texas

Résumé

Des solutions pour le mouvement solaire par rapport à 12 membres classiques du Groupe Local restreint et 9 membres possibles d'un Groupe Local étendu, tous à moins de 2 mégaparsecs, suggèrent que le Groupe Local (restreint ou étendu) est en expansion au taux de $\mathrm{H}^{\star}=47 \pm 12$ ou $57 \pm 11 \mathrm{~km} \mathrm{~s}^{-1} \mathrm{Mpc}^{-1}$, qui est nettement moindre que sa valeur $\mathrm{H}_{0}=$ $90 \mathrm{~km} \mathrm{~s}^{-1} \mathrm{Mpc}^{-1}$ dans I'espace extérieur au super-amas local. Les effets de rotation différentielle prévus par le modèle cinématique du super-amas local sont mis en évidence.

Le mouvement solaire par rapport au centre des vitesses du Groupe Local est $v_{0}=340 \pm 18 \mathrm{~km} \mathrm{~s}^{-1}$ vers un apex aux coordonnées galactiques $1=105^{\circ} \pm 5^{\circ}, \mathrm{b}=-11^{\circ} \pm 3^{\circ}$. Compte tenu des valeurs conventionnelles du mouvement solaire dans la Galaxie, 1 'apex du centre galactique dans le Groupe Local est aux coordonnées supergalactiques $\mathrm{L}=325^{\circ} \pm 11^{\circ}$, $\mathrm{B}=-12^{\circ} \pm 11^{\circ}$ avec une vitesse $\mathrm{V}_{\mathrm{G}}=140 \pm 25 \mathrm{~km} \mathrm{~s}^{-1}$.

La dispersion des vitesses résiduelles $\sigma=40$ à $50 \mathrm{~km} \mathrm{~s}^{-1}$ correspond par le théorème du viriel à une masse totale $H \mathrm{C}_{\mathrm{VT}} \simeq 9 \times 10^{11} \mathrm{H}_{\mathrm{O}}$ qui ne dépasse guère celle de la somme des galaxies et nuages gazeux intergalactiques qui font partie du Groupe Local. 


\section{SOLAR MOTION WITH RESPECT TO THE NEAREST GALAXIES}

G. de Vaucouleurs, W.I. Peters and H.G. Corwin, Jr. Department of Astronomy and McDonald observatory The University of Texas

\section{Abstract}

Solutions for solar motion with respect to 12 classical members of the restricted Local Group and 9 additional proposed members of an extended Local Group, all within 2 Mpc, suggest that the Local Group - both restricted and extended - is expanding at a rate, $\mathrm{H}^{*}=47 \pm 12$ to $57 \pm 11 \mathrm{~km} \mathrm{~s} \mathrm{~s}^{-1} \mathrm{Mpc}^{-1}$, which is significantly lower than its free-space (asymptotic) value $\mathrm{H}_{0} \simeq 90 \mathrm{~km} \mathrm{~s}^{-1} \mathrm{Mpc}^{-1}$, as required by the rotatingexpanding model of the Local supercluster. The differential rotation effects predicted by the model are detectable in the velocity residuals with correct phase $L_{0}^{*}=87^{\circ}$ and amplitude $A^{*}=30$ to $40 \mathrm{~km} \mathrm{~s}^{-1} \mathrm{Mpc}^{-1}$ in the first-order expansion.

$$
V=H^{*} r+V_{\odot} \cos A+A * r \sin 2\left(I-L_{O}^{*}\right) \cos ^{2} B
$$

The solar motion with respect to the velocity centroid of the Local Group is $V_{0}=340 \pm 18 \mathrm{~km} \mathrm{~s}^{-1}$ toward the apex $1=105^{\circ} \pm 5^{\circ}, \mathrm{b}=-11^{\circ} \pm 3^{\circ}$. With the conventional values of the solar motion within the Galaxy the apex of the galactic center in the Local Group is at supergalactic coordinates $\mathrm{I}=325^{\circ} \pm 11^{\circ}, \mathrm{B}=-12^{\circ} \pm 11^{\circ} \mathrm{with}$ a velocity $\mathrm{V}_{\mathrm{G}}=140 \pm 25$ $\mathrm{km} \mathrm{s} \mathrm{s}^{-1}$.

The residual velocity dispersion $\sigma=40$ to $50 \mathrm{~km} \mathrm{~s}^{-1}$ implies a virial theorem mass $r_{V T} \simeq 9 \times 10^{11} r_{0}$ not significantly in excess of that which can be accounted for by the member galaxies and intergalactic gas clouds. 

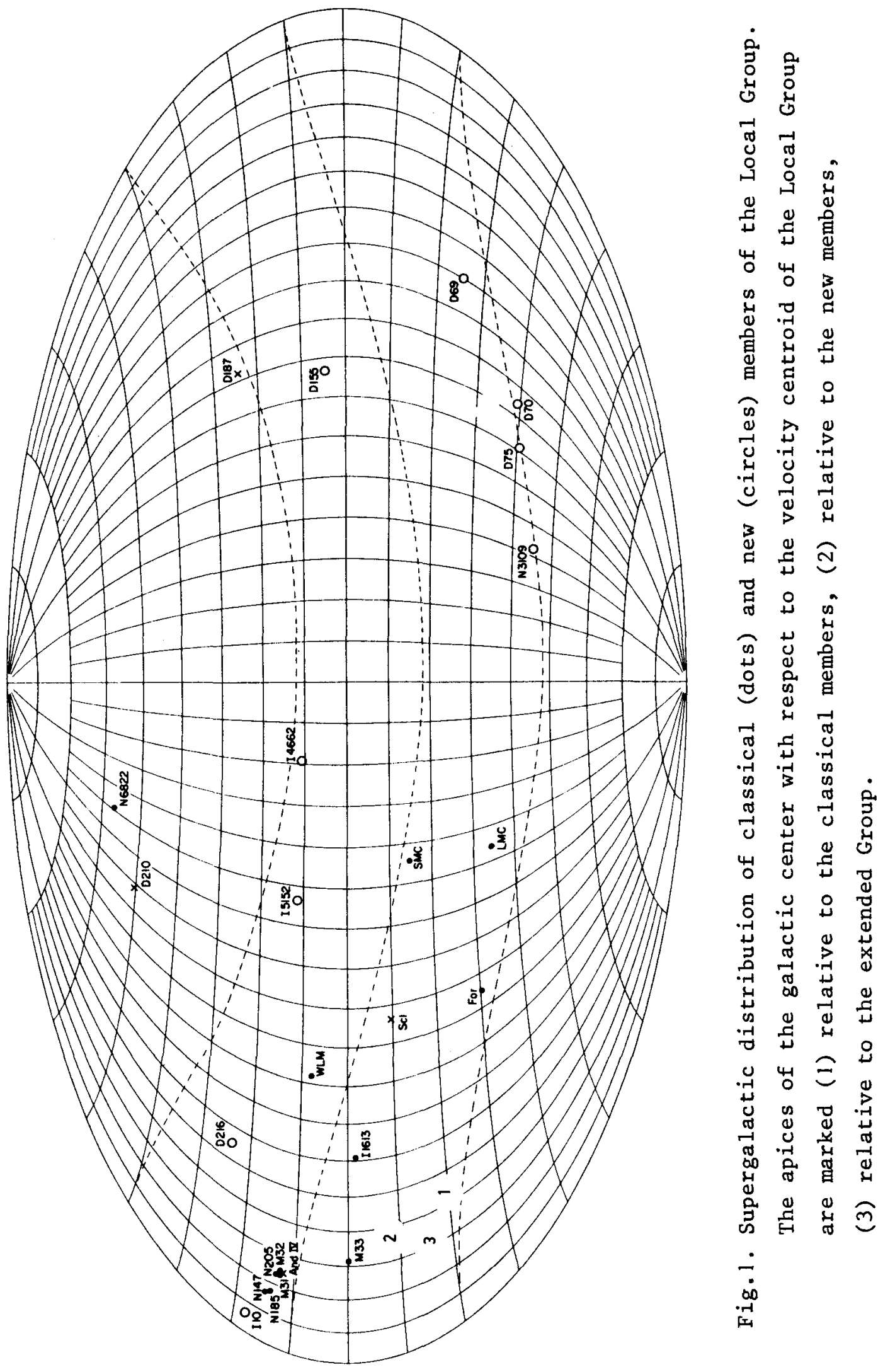


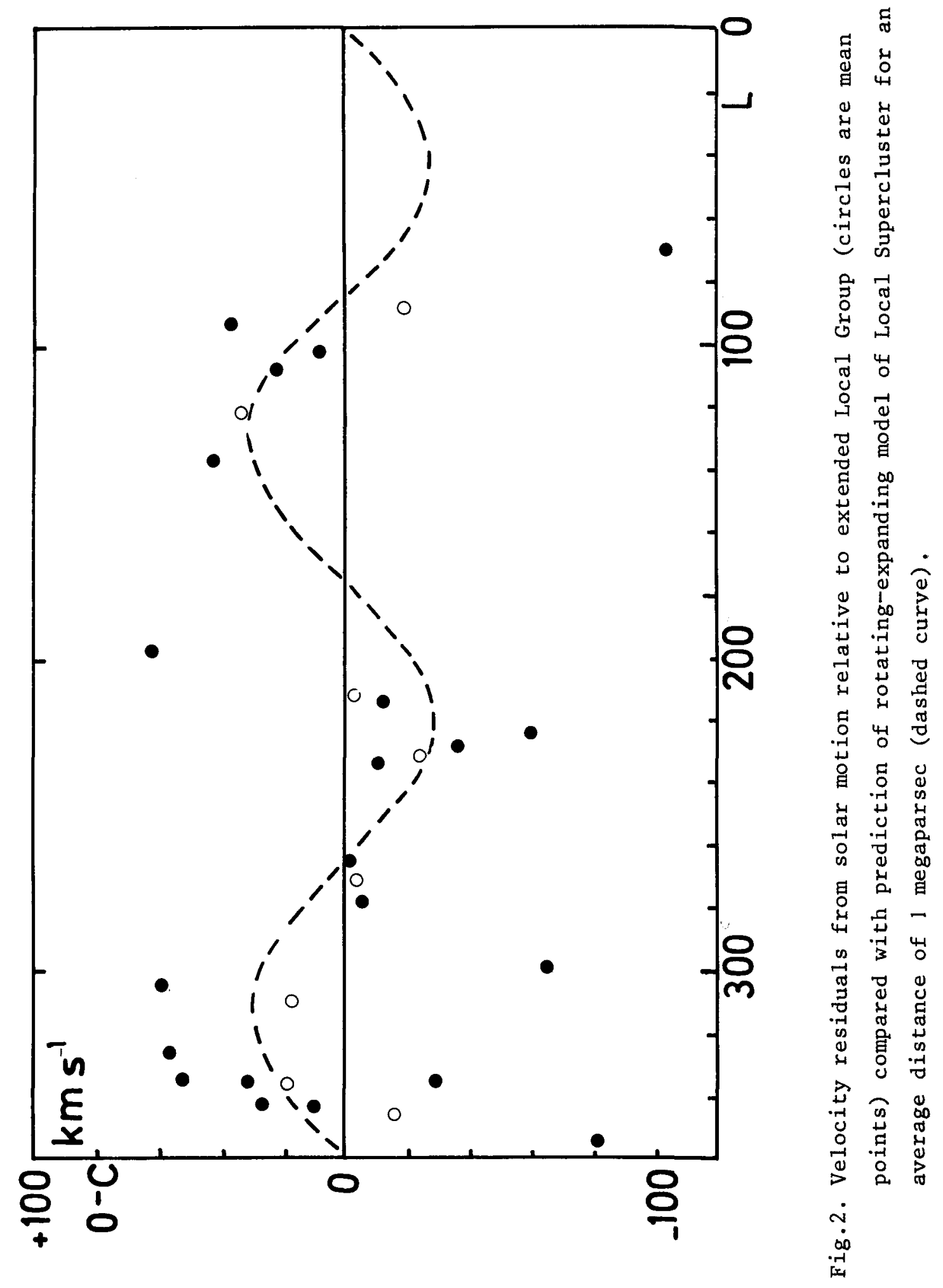




\section{DISCUSSION}

A. YAHIL: 1) The solution for the expansion parameter depends on the choice of sample. Using only the certain members I even obtained a collapse of the Local Group, but the result was not significant.

2) The value I obtain for the motion of the Sun relative to the Local Group is $\mathrm{V}_{0}=308 \pm 23 \mathrm{~km} \mathrm{~s}{ }^{-1} ; 1=105^{\circ} \pm 5^{\circ} ; \mathrm{b}=-7^{\circ} \pm 4^{\circ}$, a somewhat lower velocity than the speaker's. However, it should be stressed that this velocity includes the rotation velocity, which is very uncertain. Hence, the motion of the Galaxy relative to the Local Group is not known with certainty.

S. WHITE: If you consider a mass-weighted mean radius or a radius of gyration of the Local Group instead of a number - weighted mean, you presumably no longer get an expansion since M 31 is moving towards us. Are these radii not more relevant?

G. DE VAUCOULEURS: A mass-weighted solution is impossible since it reduces the Local Group to 2 objects (M 31) and the Galaxy). The traditional solution equal weights for all members gives a very good $V(\cos A)$ diagram, a well-defined, stable solution and no evidence for equipartition of energy between low and high-mass members.

J.M. BARNOTHY: We have observed the sidereal time periodicity of cosmic radiation from 1929 to 1942 with several cosmic ray telescopes. Presently the largest cosmic ray telescopes are at the Nagoya University in Japan. It has been proved that in the sidereal time periodicity of cosmic radiation the amplitude corresponds to a solar velocity of about $250 \mathrm{~km} / \mathrm{s}$, in a direction of about $90^{\circ}$ galactic longitude end zero latitude. These values agree with the observations of de Vaucouleurs. 